\title{
TWO-YEARS WATER DEGRADATION OF BULK-FILL RESIN COMPOSITE BONDED TO CERVICAL DENTIN
}

\author{
Yasser A. Abed ${ }^{*}$ and Nabawy A. Alrobeigy**
}

\begin{abstract}
Objective: To evaluate the effect of two years water storage on micro tensile bond strength of bulk-fill composite restorations bonded to cervical dentin.

Materials and Methods: Mesial and distal class II slot Cavities were prepared in each of 64 human lower molars. The prepared teeth were randomly divided into 4 groups $(n=16)$ and restored with QuiXfil (high viscosity bulk-fill composite), X-tra fil (high viscosity bulk-fill composite), Filtek Bulk Fill (low viscosity bulk-fill composite), and Grandio (incremental-fill conventional composite), respectively. All composite materials bonded with Futurabond NR, single step selfetch adhesive. Then, the restored teeth of each group were subdivided into two subgroups $(n=8)$ according to water storage period: 24 hours and 2 years. Each sample was sectioned into micro bars, after storage, and subjected to micro-tensile bond strength test using a universal testing machine. Failure modes after debonding were recorded and some representative samples were evaluated by SEM.
\end{abstract}

Results: At 24-hours, Grandio recorded significant higher $\mu$ TBS in comparison to all other bulk-fill composites. X-tra fil had the significant lowest $\mu$ TBS of the tested bulk-fill composites. After 2-years of water storage, a significant reduction in $\mu$ TBS mean values of Grandio and QuiXfil were observed, while that of the other materials not affected. Most of failure modes either at 24-hours or after 2-years were adhesive in nature.

Conclusion: Incremental-fill composite (Grandio) provide initial higher bond strength to cervical dentin, while that of two of the bulk-fill composites (X-tra fil and Filtek Bulk Fill) was not deteriorated by water storage for 2 years.

KEYWORDS: Bulk fill composite; Self-etch adhesives; Micro tensile bond strength; Cervical dentin.

* Lecturer, Department of Operative Dentistry, Faculty of Dentistry, October 6 University, Egypt.

** Assistant Professor, Department of Dental Biomaterials, Faculty of Dentistry, Tanta University, Egypt. 


\section{INTRODUCTION}

With the advancement of dental materials and techniques, Composites have become the most widely used direct esthetic restorative materials. ${ }^{1}$ Polymerization shrinkage still a major drawback of Composite resin restorations, ${ }^{2-5}$ which generates stress at the tooth-restoration interface, resulting in debonding when the shrinkage stress surpass the bond strength. ${ }^{6}$

Commonly, incremental application of the Composite resin is needed to minimize the stress from polymerization shrinkage. ${ }^{1,6-8}$ Recently, a new generation of so-called "bulk-fill" Composite has been introduced on the market, enabling up to 4 $\mathrm{mm}$ thick increments to be cured in one step, thus skipping the time-Consuming layering technique..$^{5,9}$ Increased translucency due to decreased filler load and increased filler size is considered to be the reason for the enhanced depth of cure of the bulk fill Composite..$^{10,11}$

According to viscosity, bulk-fill Composites classified into two classes: high-viscosity and lowviscosity Composites. High viscosity Composites contain a greater amount of inorganic filler and are much more resistant to slumping. While, lowviscosity Composites contain lower filler content leading to inferior mechanical properties, so that they must be capped with a layer of high viscosity Composite..$^{10,12}$

Reliable and durable bonding of resin Composites to the tooth substrate has long been desired in restorative dentistry. ${ }^{13,14}$ Advances in adhesive technology have facilitated restoration of many tooth defects by direct resin Composite placement. ${ }^{15}$ Recently, single-step self-etch adhesives, which combine the functions of conditioner, Primer and bonding resin, have been developed to simplify and shorten the clinical procedure of composite restorations. ${ }^{16}$

Self-etch adhesives consist of non-rinsing acidic monomers dissolved in an aqueous solution and/or organic solvents relying on their ability to infiltrate through smear layers to generate a hybrid layer with mineral incorporated. ${ }^{17}$ Numerous of the current self-etch adhesives have shown excellent immediate bond strength values, but they usually do not have the same behavior in long term studies. ${ }^{18-20}$

Water storage are accepted ageing strategy to challenge the durability of the resin-dentin bonds. ${ }^{13,21}$ Water degradation may occur due to collagen or polymer hydrolysis. The former is commonly related to total etch systems due to the poor resin infiltrated zone with naked collagen fibrils that are highly susceptible to hydrolysis. The latter was observed in both total-etch and self-etch adhesive systems and depends on factors such as the composition of the adhesive systems. ${ }^{22}$

Micro-tensile bond strength test are one of the most frequently used tests to screen adhesives. The rational behind this is that the stronger the adhesion between tooth structure and adhesives, the better it will resist stress imposed by resin polymerization and oral function, leading to more durable restorations. ${ }^{18,23}$

Up to now, an incremental filling technique has been the standard to decrease the polymerization contraction stress and to achieve an adequate bond strength of composite to tooth structure. ${ }^{(6)}$ For the purpose to evaluate if the cavity can be filled at once and avoid the long procedure of incremental layering technique, the performance of bulk-fill flowable composites, immediately after restorations or after long-term water storage, needs to be evaluated in deep and narrow cavities. The high $\mathrm{C}$-factor of these cavities limit to a great extent stress relief and the contraction stress might exceed the bond strength. ${ }^{(24,25)}$ Furthermore, mechanical properties of the composite adjacent to the interface might be negatively affected due to the high reduction in light intensity before reaching the bottom of the cavity. ${ }^{(26)}$ Therefore, the objective of this study was to evaluate the effect of two-years water storage on micro-tensile bond strength of bulk-fill composites to cervical dentin of class II cavities, in comparison 
to incremental-fill composite. The tested null hypothesis was that similar bond strength values to cervical dentin are obtained by bulk-fill and incremental-fill composites, either at 24-hours or after 2-years of water storage.

\section{MATERIALS AND METHODS}

\section{Materials}

Three bulk-fill resin composites (two high viscosity; QuiXfil and X-tra fil; and one flowable; Filtek Bulk Fill ) and one incremental-fill composite (Grandio) were used in this study. The list of composites, manufactures, types, and chemical compositions are presented in table 1.

\section{Specimens preparation}

Sixty four human sound lower molars extracted as results of diabetic complications were collected, cleaned and stored in $0.5 \%$ chloramine solution at $4^{\circ} \mathrm{C}$. The teeth were used within three month after extraction. The root of each tooth was embedded in a cylindrical Teflon mold up to $4 \mathrm{~mm}$ below cemento-enamel junction with cold curing acrylic resin. The occlusal surfaces were ground flat at the level of marginal ridges using a flat end cylindrical fissure diamond bur (Komet, Lemgo, Germany) operated in a high-speed hand-piece under copious water coolant to obtain a flat surface, $4 \mathrm{~mm}$ above the cementum-enamel junction and perpendicular to the long axis of the tooth.

TABLE (1) Materials specifications

\begin{tabular}{|c|c|c|c|}
\hline Product & Manufacture & Type\&shade & Chemical Composition \\
\hline $\begin{array}{l}\text { QuiXfil } \\
\text { (High viscosity } \\
\text { bulk-fill) }\end{array}$ & $\begin{array}{l}\text { Dentsply, } \\
\text { Konstonz, } \\
\text { Germany. } \\
\text { Lot: } 12001464\end{array}$ & $\begin{array}{l}\text { Micro-hybrid } \\
\text { Shade: } \\
\text { universal }\end{array}$ & $\begin{array}{l}\text { Resin: UDMA, TEGDMA, Di and Tri methacrylate. } \\
\text { Filler: Strontium-alumino-sodium-fluoro-phosphate-silicate } \\
\text { glass (0.1-4.5- } \mu \mathrm{m}) \text {. } \\
\text { Filler loading: } 85.5 \% \text { by weight. }\end{array}$ \\
\hline $\begin{array}{l}\text { X-tra fil } \\
\text { (High viscosity } \\
\text { bulk-fill) }\end{array}$ & $\begin{array}{l}\text { Voco, Guxhaven } \\
\text { Germany. } \\
\text { Lot: } 1343523\end{array}$ & $\begin{array}{l}\text { Micro-hybrid } \\
\text { Shade: } \\
\text { universal }\end{array}$ & $\begin{array}{l}\text { Resin: Bis-GMA, UDMA, TEGDMA. } \\
\text { Filler: Barium-boron-alumino-silicate-glass }(2-3 \mu \mathrm{m}) \text {. } \\
\text { Filler loading: } 86 \% \text { by weight. }\end{array}$ \\
\hline $\begin{array}{l}\text { Filtek Bulk Fill (Low } \\
\text { viscosity bulk-fill) }\end{array}$ & $\begin{array}{l}3 \mathrm{M}, \mathrm{ESPE}, \\
\text { St paul, MN, USA. } \\
\text { Lot: } \mathrm{N} 446835\end{array}$ & $\begin{array}{l}\text { Micro-hybrid } \\
\text { Shade: A3 }\end{array}$ & $\begin{array}{l}\text { Resin: Bis-GMA, UDMA, Bis-EMA, procrylate resins. } \\
\text { Fillers: Zirconia /silica }(0.01-3.5 \mu \mathrm{m}), \mathrm{Ybf}(0.02-5 \mu \mathrm{m}) \text {. } \\
\text { Filler loading: } 64.5 \% \text { by weight. }\end{array}$ \\
\hline $\begin{array}{c}\text { Grandio } \\
\text { (incremental-fill) }\end{array}$ & $\begin{array}{l}\text { Voco, Guxhaven, } \\
\text { Germany. } \\
\text { Lot: } 1230507\end{array}$ & $\begin{array}{l}\text { Nano-hybrid } \\
\text { Shade: A3 }\end{array}$ & $\begin{array}{l}\text { Resin: Bis-GMA, TEGDMA } \\
\text { Filler: Barium-boron-alumino-silicate glass }(0.1-2.5 \mu \mathrm{m}) \text {, } \\
\text { silica ( } 20-60 \mathrm{~nm}) \text {. } \\
\text { Filler loading: } 87 \% \text { by weight }\end{array}$ \\
\hline Futurabond NR & $\begin{array}{l}\text { Voco, Guxhaven, } \\
\text { Germany. } \\
\text { Lot: } 1231039\end{array}$ & $\begin{array}{l}\text { One step } \\
\text { self-etch } \\
\text { adhesive }\end{array}$ & $\begin{array}{l}\text { Liquid A: Water, ethanol, silicon dioxide. } \\
\text { Liquid B: Acid modified methacrylate (methacrylate ester) } \\
\text { HEMA, Camphorquinone. } \\
\text { filled with Nanoparticles. }\end{array}$ \\
\hline
\end{tabular}

Bis-GMA: bisphenol A glycidly dimethacrylate; UDMA: Urethan dimethacrylate; TEGDMA: Triethyene glycol dimethacrylate; Bis- EMA: Bisphenol-A polyethylene glycol diether; Ybf: Ytterbium trifluoride. 
Proximal class II slot cavities with dimensions of $2 \mathrm{~mm}$ depth, $4 \mathrm{~mm}$ width and $4 \mathrm{~mm}$ height (gingival wall at the cemento-enamel junction) were prepared on the mesial and distal surface of each molar using a \# C21 carbide bur (Jota, Swiss) mounted in a high-speed water-cooled hand-piece. New bur were used after every five preparations. The dimensions for all cavity configurations were verified using a periodontal probe and digital caliper (I.O.S digital caliper, USA). All cavity preparations were made by one operator. The prepared molars were randomly divided into four groups $(n=16$; 32 proximal cavities) according to the composite restorative material as follows: group I, QuiXfil (high viscosity bulk-fill composite); group II, X-tra fil (high viscosity bulk-fill composite); group III, Filtek Bulk Fill (low viscosity bulk-fill composite); group IV, Grandio (incremental-fill conventional composite).

Futurabond NR single step self-etch adhesive was used as a bonding agent for all composites used in this study. A tofflemire matrix retainer with a metal band was utilized during application of the adhesive and the composite resin. In order to avoid extension of material at the gingival margin, the matrix was tightened and held by finger against the gingival margin of the Cavities. Adhesive and composite material of each group were applied into their respective cavities according to the manufacturer's instructions. QuiXfil, X-tra fil, and Filtex Bulk Fill were applied in one increment, while Grandio was applied in two horizontal increments. LED curing unit (Blue phase $\mathrm{C}^{8}$, Ivoclar Vivadent) with a light intensity of $850 \mathrm{mw} / \mathrm{cm}^{2}$ was used for photo polymerization.

After preparation and resin composite application, the teeth of each group were subdivided into two sub-groups, named 24-hours and 2-years, based on storage period. For 24-hours sub-group $(n=8)$ : the teeth were stored in distilled water at $37{ }^{\circ} \mathrm{C}$ for 24 hours, then micro-tensile bond strength measurements were carried out. For 2-years sub-group $(n=8)$ : the teeth were stored in
$0.5 \%$ chloramines $\mathrm{T}$ solution, to prevent bacterial growth, at $37{ }^{\circ} \mathrm{C}$ for 2 years before micro-tensile bond strength measurements were carried out.

\section{Micro-tensile bond strength test}

After storage to the planned period for each sub-group of each composite group, each tooth with its resroration was sectioned longitudinally, perpendicular to the adhesive interface, mesiodistally and buccolingually into $1 \mathrm{~mm} \times 1 \mathrm{~mm}$ rectangular bars using a water-cooled low speed diamond saw (Isomet 1000, Buehler Ltd, Lake Bluff, Il, USA), then the mounted tooth are rotated $90^{\circ}$ and sectioned at $4 \mathrm{~mm}$ below cemento-enamel junction. This serial sectioning leads to formation of two to four square beams from each molar. For each sub-group, 20 beams were selected. Each beam was attached to the flat grips of a microtensile device with cyanoacrylate glue, and tested in tension in a universal testing machine (Model LRX-plus, Lloyd Instruments Ltd., Fareham, UK) at a crosshead speed of $0.5 \mathrm{~mm} / \mathrm{min}$ until failure. After testing, the specimens were carefully removed from the fixtures with a scalpel blade and the cross-sectional area at the site of fracture measured to the nearest $0.01 \mathrm{~mm}$ with a digital caliper (I.O.S digital caliper, USA). The cross-sectional area of each beam $\left(\mathrm{mm}^{2}\right)$ was divided by the peak tensile load at failure $(\mathrm{N})$ to calculate stress at fracture $\left(\mathrm{MP}_{\mathrm{a}}\right)$.

The failure modes of fractured specimens were examined using USB digital microscope (Scope Capture Digital microscope, Guangdong, china) at 25X magnification by a single operator and classified as adhesive, cohesive or mixed. Failure mode was considered adhesive when it occurred at the dentin or composite/adhesive interface; cohesive when the failure occurred in dentin or composite; or mixed, when adhesive and cohesive failures occurred simultaneously. Some representative samples of each subgroup were prepared for SEM (JEOL, JSM T330, Japan) analysis according to methodology of Nakabayashi and Takarada. ${ }^{27}$ 


\section{Statistical analysis}

One way ANOVA followed by pair-wise student Newman Keuls post-hoc tests were performed to detect significance among groups. Paired t-tests were performed to detect significance between the two sub-groups (24-hours vs 2-years) of each composite material. Chi square test was done for comparison of different failure modes. $\mathrm{P}$ values $\leq$ 0.05 were considered to be statistically significant in all tests.

\section{RESULT}

The mean and standard deviation $( \pm \mathrm{SD})$ of the $\mu$ TBS outcomes are shown in table (2). Oneway ANOVA showed that there were significant differences in $\mu$ TBS mean values among materials (either at 24-hours or 2-years) or between the two subgroups of each material (24-hours vs 2-years).

At24-hours, Grandio(incremental-fillcomposite) group recorded the highest statistically significant $(\mathrm{P}<0.05) \mu$ TBS mean value in comparison to all bulk-fill composites tested. Regarding bulk-fill composites, Filtek Bulk Fill and QuiXfil showed statistically comparable $\mu$ TBS mean values, which are statistically significantly $(\mathrm{P}<0.05)$ higher than that of X-tra fil.

At 2-years, no significant diffirences in $\mu$ TBS mean values was seen between Grandio (incremental- fill composite) and Filtek Bulk Fill (low viscosity bulk-fill composite) or between QuiXfil and X-tra fil (high viscosity bulk-fill composites). At the same time, the $\mu$ TBS mean values of Grandio and Filtek Bulk Fill were significantly $(\mathrm{P}<0.05)$ higher than those of QuiXfil and X-tra fil.

After 2-years water storage, the $\mu \mathrm{TBS}$ mean values of all composites tested were reduced compared to their respective 24-hour results, but the reduction was significant $(\mathrm{P}<0.05)$ for Grandio and QuiXfil only.

The frequent distribution (\%) of failure modes are listed in table 3. Representative SEM images of different failure patters are shown in figures 1-4. Surface analysis of the fractured microbars revealed that all types of failure were seen. The predominant failure mode for all groups, either at 24-hours or after 2-years, was adhesive. Cohesive failure was observed either in dentin or in composite and at the same time it was the least frequently occurred in all groups. However, the differences in the failure modes frequency among groups, either at 24-hours or after 2-years of water storage, were statistically non-significant as indicated by chi square test $(\mathrm{P}>0.05)$. Also, the failure modes of each material after 2-years of water storage were not significantly ( $\mathrm{P}>0.05)$ different compared to that at 24-hours.

TABLE (2) Micro-tensile bond strength results (Means, MPa; and SDs) as function of composite and water storage.

\begin{tabular}{|c|c|c|c|c|c|c|}
\hline \multirow{3}{*}{ Group } & \multirow{3}{*}{ Material } & \multicolumn{4}{|c|}{ Water storage } & \multirow{3}{*}{$\begin{array}{c}\mathrm{t} \text {-test } \\
\text { (P value) }\end{array}$} \\
\hline & & \multicolumn{2}{|c|}{ 24-hours } & \multicolumn{2}{|c|}{ 2-years } & \\
\hline & & Mean & SD & Mean & SD & \\
\hline I & QuiXfil & $50.04^{\mathrm{Ba}}$ & 3.65 & $32.26^{\mathrm{Bb}}$ & 6.66 & $0.0003^{*}$ \\
\hline II & $\mathrm{X}$-tra fil & $38.68^{\mathrm{Ca}}$ & 6.29 & $34.71^{\mathrm{Ba}}$ & 2.71 & 0.2845 (NS) \\
\hline III & Filtek Bulk Fill & $54.40^{\mathrm{Ba}}$ & 6.57 & $51.56^{\mathrm{Aa}}$ & 12.06 & 0.7690 (NS) \\
\hline IV & Grandio & $73.46^{\mathrm{Aa}}$ & 9.66 & $57.96^{\mathrm{Ab}}$ & 8.36 & $0.0436^{*}$ \\
\hline ANOVA & (P value) & \multicolumn{2}{|c|}{$0.0001 *$} & \multicolumn{2}{|c|}{$0.001 *$} & \\
\hline
\end{tabular}

Different super case letters in the same column indicating statistically significant differences $(p<0.05)$.

Different lower case letters in the same raw indicating statistically significant differences $(p<0.05)$.

* Significant; NS: not significant; SD: standard deviation. 
TABLE (3) Frequent distribution (\%) of failure Modes for all composites tested.

\begin{tabular}{|c|c|c|c|c|c|c|c|c|}
\hline \multirow{3}{*}{ Group } & \multirow{3}{*}{ Material } & \multicolumn{6}{|c|}{ Failure modes } & \multirow{3}{*}{$P$ value } \\
\hline & & \multicolumn{3}{|c|}{ 24-hours water storage } & \multicolumn{3}{|c|}{2 -years water storage } & \\
\hline & & Adhesive & Cohesive & Mixed & Adhesive & Cohesive & Mixed & \\
\hline I & QuiXfil & 50 & 20 & 30 & 60 & 10 & 30 & \multirow{4}{*}{$\begin{array}{c}0.1469 \\
(\mathrm{NS})\end{array}$} \\
\hline II & X-tra fil & 60 & 10 & 30 & 60 & 10 & 30 & \\
\hline III & Filtek Bulk Fill & 50 & 20 & 30 & 50 & 10 & 40 & \\
\hline IV & Grandio & 50 & 30 & 20 & 50 & 20 & 30 & \\
\hline
\end{tabular}

\section{NS: not significant}

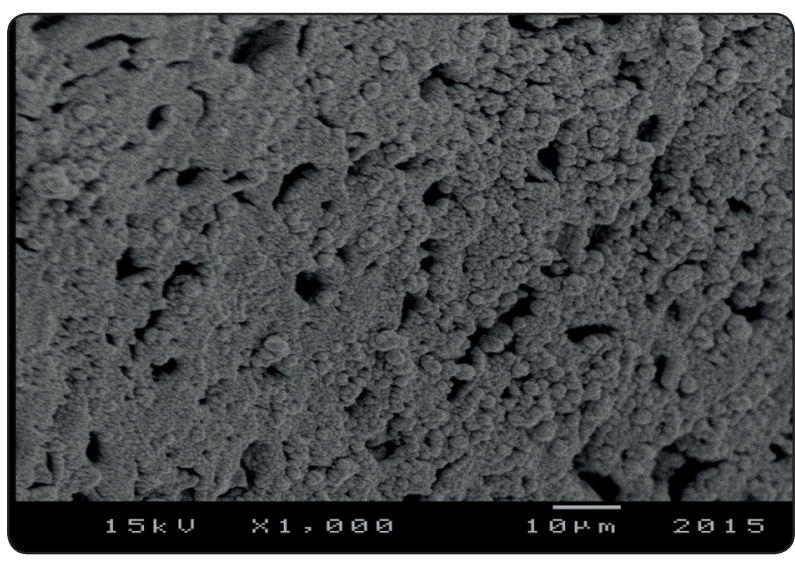

Fig. (1) SEM image of a fractured surface of QuiXfil after 2-years water storage showing an adhesive failure pattern. Failure occurred at the top of the hybrid layer with a resin impregnation partially occlude the dentinal tubules.

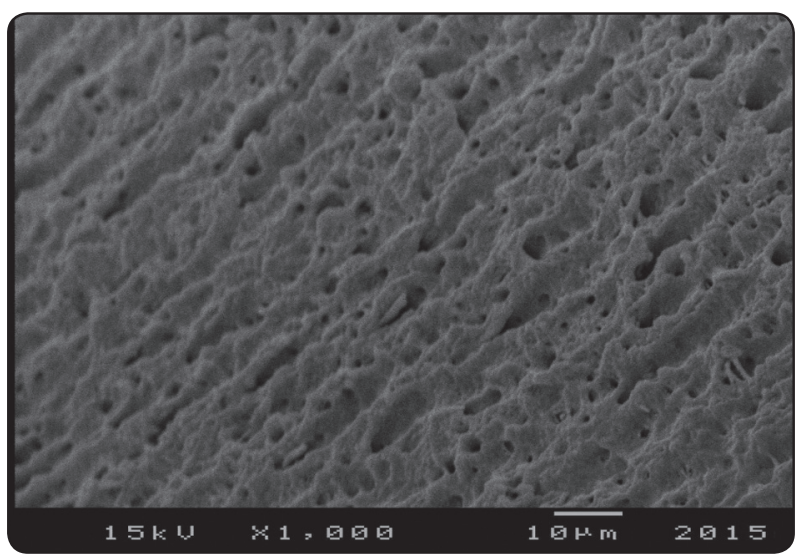

Fig. (3) SEM image of cohesive failure within dentin for fractured Filtek Bulk Fill after 24 hour water storage. Resin was lost and dentinal tubules are empty.

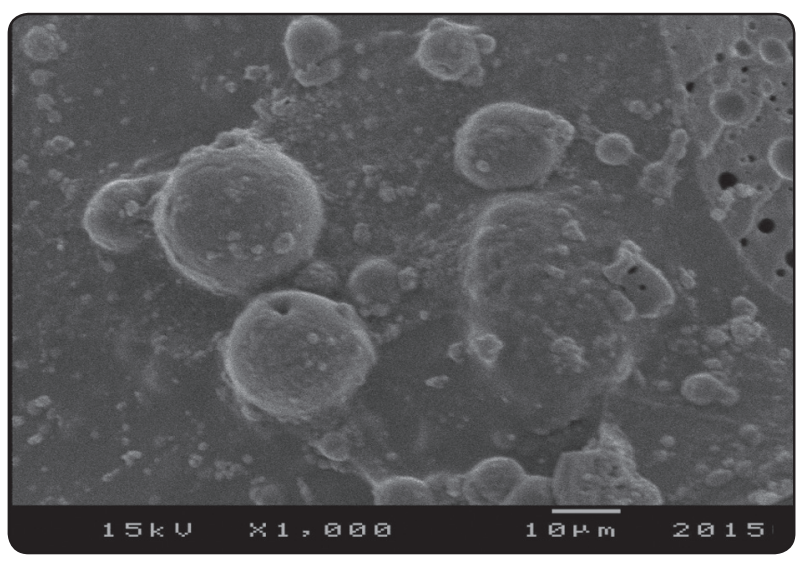

Fig. (2) SEM image of a fractured surface of X-tra fil after 2-years water storage showing a cohesive failure in composite.

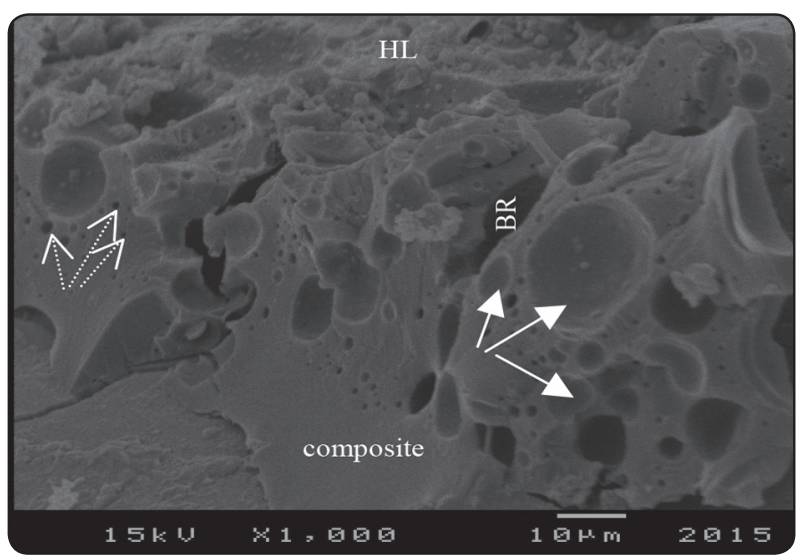

Fig. (4) SEM image of a fractured surface of a Grandio after 2 year water storage showing a mixed failure pattern. BR: bonding resin. HL: hybrid layer. Arrows indicate to large air voids, which might be due to inclusion of air bubbles during composite application. Dash arrows point to small voids that might be related to water sorption. 


\section{DISCUSSION}

The recently introduced bulk-fill composites appears to simplify the restoration technique and reducing the chair time required for restorations. ${ }^{5}$ several in vitro studies have confirmed that the bulk-fill material tested could be cured in $4 \mathrm{~mm}$ layers., ${ }^{3,528}$ Higher curing depth of the bulk fill composites has been achieved by either, a higher translucency of the resin material to allow a deeper penetration of the polymerizing light. ${ }^{11}$ or adding new photo-initiators like the benzoyl germanium derivatives which significanthy increased the reactivity of the monomer and hence the depth of cure. ${ }^{29}$ On the other hand, the layering technique is sensitive, time consuming and bear certain risks, such as incorporating air voids and contamination between the layers..$^{30,31}$

Futurabond NR, single step self-etch adhesive, was used to bond all composites in this study in order to facilitate standardized conditions, thereby allowing us to focus on the variables related to the material and water aging. Discrepant results might be observed if each composite was bonded with the corresponding adhesive system recommended by the manufacturers. The selfetching adhesives offer some advantages over etchand-rinse adhesives systems such as reduction of postoperative sensitivity, less sensitive technique and simplification of bonding procedures because they do not require a separate acid conditioning step and moist post-rinse control. ${ }^{32}$ Self-etching adhesives are composed of aqueous solution of acidic functional monomers. ${ }^{33}$ water is necessary to provide the medium for ionization and action of these acidic resin monomers. HEMA monomer is added because most acidic monomers have a low solubility in water, while bi-or multi-functional monomers are important to provide strength to the cross-linking at the formed polymer matrix. ${ }^{34}$ It was believed that inadequate resin penetration would not occur with self-etch adhesives because etching and priming occur simultaneously. ${ }^{35}$ Unfountnatly, these adhesives have recently demonstrated resin free demineralized area which was attributed to continuous etching. ${ }^{36}$

Based on the results obtained in the present study, the formulated null hypothesis has to be rejected. At 24-hours evaluation, the incremental filling technique with Grandio composite showed significantly higher $\mu$ TBS than all other bulk-fill composites. These results seem to be logical as many authors reported that incremental packing of composite resin minimizes the stress from polymerization shrinkage and promotes adequate mechanical properties of the composite resin material. ${ }^{1,6-8}$ In addition, the incremental layering of the composite reduces the $\mathrm{C}$-factor, which in turn reduces the shrinkage stress at the tooth-composite interface by permitting the stress-relieving flow of composite from the unbonded surface towards the bonded surface. ${ }^{24}$ Therefore, minimizes the harmful effects of stress development at the tooth-adhesive interface, which may improve the micro-tensile bond strength to cervical dentin. ${ }^{37}$ Reis et al. ${ }^{38}$ also achieved low bond strength values of bulk fill compared to incremental-fill composites, which are in line with our results and mentioned that this may be contributed to two factor: high polymerization contraction stress generated at resin-dentin interface during light curing of a great amount of composite $\operatorname{resin}^{39}$ or decrease polymerization effectiveness at the bottom of the cavity. ${ }^{40}$ Regarding bulk-fill groups, Filtek Bulk Fill showed higher significant $\mu$ TBS than X-tra fil and higher non-significant $\mu$ TBS in comparison to QuiXfil, which could be explained by the exclusion of TEGDMA monomer from the chemical formulation of Filtek Bulk Fill. TEGDMA has approximately half $(286 \mathrm{~g} / \mathrm{mol})$ the molecular weight of the other used monomers such as Bis-GMA (512 g/mol) Bis-EMA (496 g/mol) and UDMA $(470 \mathrm{~g} / \mathrm{mol}){ }^{3}$ Therefore shrinkage could be reduced by decreasing the numbers of reactive sites per unit volume and hence bond strength is increased..$^{41}$ Furthermore, in a study under taken to evaluate the effect of the resin matrix composition of experimental composite on their polymerization 
shrinkage and rheological properties, the authors concluded that the substitution of UDMA for TEGDMA reduces the shrinkage stress level. ${ }^{42}$

After 2-years of water storage, the significant reduction in $\mu$ TBS values of QuiXfil and Grandio might be due to the degradation of resin-dentin bond, which is usually attributed to the degradation of un-protected collagen fibrils at the base of hybrid layer or to the hydrolytic degradation that polymers are prone to after water sorption. Water can infiltrate in the resin matrix and through swelling can reduce the frictional forces between the polymer chains, in a process known as plasticization. This water-driven process can therefore, decrease the mechanical properties of the polymer matrix ${ }^{43}$ and cause elution of uncured monomers ${ }^{44}$. Also, evidence has demonstrated that the breakdown of un-protected collagen fibrils can occur via activation of hostderived matrix metalloproteinase. ${ }^{45}$ On the other hand, the $\mu$ TBS of Filtek Bulk Fill didn't affected by long-term water storage for 2 years and it is significantly higher than that of QuiXfil and X-tra fil. Some authors reported no decrease in bond strength of self-etch adhesive containing fluoride after water aging for 6 month plus thermocycling, ${ }^{46}$ and after water storage for 1 years. ${ }^{47,48}$ They reported that fluoride can react with ingredients beneath the subhybrid layer to remineralize the dentin substrate. According to Nikaido et al., ${ }^{49}$ an area referred to as the acid-base resistant zone is formed beneath the hybrid layer of self-etch adhesives containing fluoride. This zone is resistant to acid attacks and its formation has been attributed to the penetration of functional monomers and fluoride release in this group of adhesives. This reinforced dentin is referred to as super dentin and has the potential to prevent primary and recurrent caries, protecting the tooth structure mechanically, chemically and biologically. ${ }^{49}$ In the same line, the presence of fluoride in the components of Filtek Bulk Fill may contribute to the formation of this reinforced dentin layer and this could explain the unaffected $\mu \mathrm{TBS}$ of this material after 2 years of water storage.
The commonly used ageing strategy to challenge the resin-dentin bonds in vitro is that where rectangular beams $(1 \mathrm{~mm})$ are subjected to direct water exposure. ${ }^{19,21}$ Mostly the authors used a flat dentin surfaces to prepare the rectangular beams. ${ }^{18,19,50,51}$ However, in the clinical situation the resin-dentin interfaces may not be in direct contact with water since bonded enamel usually acts as a protective barrier against water diffusion. ${ }^{13}$ In addition, the $\mathrm{C}$-factor is an important factor to be considered when under taking experiments regarding the degradation and durability of resin-dentin interfaces as it may influences the polymerization stress and the bond strength. ${ }^{52}$ It's will established that posterior class I and II Cavities with a high $\mathrm{C}$-factor will result in greater stresses due to a large number of bonded surfaces. ${ }^{24,25}$ This stresses puts the resin-tooth interface under sever tension during the critical setting of the adhesive. Such pre-stressed interfaces are more susceptible to degradation by gaps and micro-voids that facilitate fluid exchange along the interface..$^{53}$

Our finding are in agreement with those reported by Hashimoto et al. ${ }^{19}$ that observed a decrease in $\mu$ TBS to dentin with two of the four self-etch adhesives tested after long-term water storage for 10 years, while the other two adhesives not affected. On the other hand some studies have reported insignificant reduction in $\mu \mathrm{TBS}$ of the self-etch adhesive after water storage for 6 month $^{48,54,55}$ and one year. ${ }^{51}$ This difference can be explained by the difference in the tested periods and site of the dentin bonded to. In another study, Abdalla and feilzer ${ }^{18}$ showed no reduction in bond strength after indirect water exposure for 4 years for all the tested adhesive. Also, this difference can be explained by the difference in cavity preparation between class I they used and class II that was used in the present study, since class II cavities have minimal thickness of enamel in the gingival margin. ${ }^{20,56}$ Since outer resin-bonded enamel has been shown to prevent water uptake, ${ }^{13,57}$ the minimal thickness of enamel in the gingival margin of class II restorations seems 
to be not enough to prevent water degradations. In addition, it has been found that the adhesive bond of resin composite to gingival margins is significantly weaker and more susceptible to failure than the bond to the axial walls, which may be contributed to unfavorable direction and high density of the dentinal tubules at the gingival area. ${ }^{58}$

Most of the failure patters were adhesive in nature, which are in agreement with several other studies. ${ }^{18,50,51,54,55}$

\section{CONCLUSIONS}

Within the limits of this in vitro study, the ability of resin based composites to absorb water plays an important role in hydrolytic degradation of resin dentin bonds as well as their application methods either incrementally or in bulk. In restorations with margin extending into dentin, bonding resin with favorable properties is needed to resist water degradation. Incremental-fill composite provided initial higher bond strength to cervical dentin. The bond strength of incremental-fill (Grandio) and one bulk-fill (QuiXfil) composites to cervical dentin was reduced by water storage for 2-years, while that of the other two bulk-fill composites not affected.

\section{REFERENCES}

1. Kwon Y, Ferracane JL, Lee IB. Effect of Layering methods, Composite type, and flowable liner on the polymerization shrinkage stress of light cured composites. Dent Mater 2012;28:801-809.

2. Braga RR, Ballester RY, Ferracane JL. Factors involved in the development of polymerization shrinkage stress in resin-composites: a systematic review. Dent mater 2005; 21:962-967.

3. Kin RJ, Kim YJ, C hoi Ns, Lee IB. Polymerization shrinkage, modulus and shrinkage stress related to toothrestoration interfacial debonding in bulk-fill composites. J Dent 2015;43:430-439.

4. Ferracame JL. Developing a more complete understanding of stresses produced in dental composites during polymerization. Dent Mater 2005; 21:36-42.
5. Do T, church B, Verissimo C, Hackmyer SP, Tantbirojn D, Simon JF, Versluis A. Cuspal flexure, Depth-of-cure, and bond integrity of bulk-fill composites. Pediatr Dent 2014;36:468-473.

6. Park J, Chang J, Ferracane J, Lee IB. How should composite be layered to reduce shrinkage stress: incremental or bulk filling? Dent mater 2008;24:1501-1505.

7. Soares CJ, Bicalho AA, Tantbirojn D, Versluis A. Polymerization shrinkage stresses in a premolar restored with different composite resins and different incremental technique. J Adhes Dent 2013;15:341-350.

8. Bicalho AA, Valdivia AD, Barreto BC, Tantbirojn D, Versluis A, Soares CJ. Incremental filling technique and composite material part II: shrinkage and shrinkage stresses. Oper Dent 2014;39: e83-e92.

9. Ilie N, Kessler A, Durner J. Influence of various irradiation processes on the mechanical properties and polymerization kinetics of bulk-fill resin based composites. J Dent 2013; 41:695-702.

10. Ilie N, Bucuta S, Draenert M. Bulk-fill resin-based composites: an in vitro assessment of their mechanical performance. Oper Dent 2013;38:618-625.

11. Bucuta S, Ilie N. Light transmittance and micromechanical properties of bulk-fill vs. conventional resin based composites. Clin Oral Invest 2014;18:1991-2000.

12. Leprince JG, Palin WM, Vanacker J, Sabbagh J, Devaux J, Leloup G. Physico-mechanical characteristcs of commercially available bulk-fill composites. J Dent 2014;42:993-1000.

13. Carvalho RM, Manso AP, Geraldelis S, Tay FR, Pashley DH. Durability of bonds and clinical success of adhesive restorations. Dent Mater 2012;28:72-86.

14. Drobac M, Stojanac I, Ramic B, Premovic M, Petrovic L. Micromor- phological characterization of adhesive interface of sound dentin and total- etch and self-etch adhesives . Med Pregl 2015;(1-2):10-16

15. Opdam NJ, Van de Sande FH, Bronkhorst E, Cenci MS, Bottenberg P, Pallesem u. Longevity of posterior composite restorations: a systematic review and meta- analysis. J Dent Res 2014;93: 943-949.

16. Miyazaki M, Tsujimoto A, Tsubota K, Takamizawa T, kurokawa H, Platt JA. Important compositional characteristics in the clinical use of adhesive systems. J Oral Sci 2014; 56:1-9.

17. Peumans M, Kanumilli P, De Munk J. Clinical effectiveness of contemporary adhesives: a systematic review of current clinical trials. Dent Mater 2005;21:864-881. 
18. Abdalla AI, Feilzer AJ. Four-years water degradation of a total - etch and two self-etching adhesives bonded to dentin. J Dent 2008;36:611-617.

19. Hashimoto M, Fujita S, Nagano F, Ohno H, Endo k. Tenyears degradation of resin-dentin bonds. Eur J Oral Scienc $2010 ; 118: 404-410$.

20. Feitosa VP, Leme AA, Sauro S, Correr-Sobrinho L, Watson TF, Sinhoreti MA, Correr AB. Hydrolytic degradation of the resin-dentine interface induced by the simulated pulpal pressure, direct and indirect water ageing. J Dent 2012;40:1134-1143.

21. Van Meerbeek B, Peumans M, Poitevin A, Mine A, Van Ende A, Neves A. Relationship between bond Strength tests and Clinical Outcomes. Dent Mater 2010 ; 26 : 100-121

22. Saboia VP, Nato F, Mazzoni A, Orsini G, Putiganano A Giannini M, Breschi L. Adhesion of a two-Step etch-andrinse adhesive On Collagen-depleted dentin .J Adhes Dent 2008;10:419-422.

23. Abdalla Al, El-Eraki M, Feilzer A. The effect of direct and indirect water storage on the micro tensile dentin bond strength of a total-etch and two self-etch adhesives. Am J Dent 2007;20:370- 374 .

24. Feilzer A, De Gee A, Davidson CL. Setting stress in composite resin in relation to configuration of the restoration. J Dent Res 1987,66:1636-1639.

25. Yoshikawa T, Sano H, Burrow MF, Tagami J, Pashley DH. Effects of dentin depth and cavity configuration on bond strength. J Dent Res 1999;78:898-905.

26. Peutzfeldt A, Asmussen E. Resin composite properties and energy density of light cure. J Dent Res 2005;84:659-62.

27. Nakabayashi N, Takarada K. Effect of HEMA on bonding to dentin. Dent Mater1992;8:125-130.

28. Heintze SD, Monrea D, Peschke A. Marginal quality of class II composite restorations placed in bulk compared to an incremental technique: evaluation with SEM and stereomicroscope. J Adhes Dent 2015;17:147-154.

29. Moszner N, Fischer uk, Ganster B, lisk R, Rheinberger $\mathrm{V}$. Benzoyl germanium derivatives as novel visible light photoinitiators for dental materials. Dent Mater 2008;24:901-907.

30. Van Kljken Jwv, Pallesen u. Randomized 3-year clinical evaluation of class I and II posterior resin restorations placed with a bulk-fill resin composite and a one-step selfetching adhesive. J Adhes Dent 2015;17:81-88.

31. Versluis A, Douglas WH, Cross M, Sakaguchi RL. Does an incremental filling technique reduce Polymerization shrinkage stresses. J Dent Res 1996;75:871-878.
32. Yoshiyama M, Matsuo T, Ebisu S, Pashley D, Regional bond strengths of self-etching/self-priming adhesive systems. J Dent 1998;26:609-616.

33. Knobloch LA, Gailey D, Azer S, Johnston WM, clelland N, Kerby RE, Bond strengths of one- and two-step selfetch adhesive systems. J Prosthet Dent 2007; 97:216-222.

34. Reis A, Loguercio AD, Carvalho RM, Grande RH. Durability of resin dentin interfaces: effects of surface moisture and adhesive solvent components. Dent Mater 2004;20:669-676.

35. Van Landuyt KL, De Munck J, Mine A, Cardoso MV, Peumans M, Van Meerbeek B. Filler debonding and subhybrid layer failures in self-etch adhesives J Dent Res. 2010;89:1045-1050.

36. Wang Y, Spencer P. Continuing etching of an all-in-one adhesive in wet dentin tubules. J Dent Res 2005; 84:350-354.

37. Perdigao J, Duarte S, Gomes G. Direct resin based composite restorations - clinical challenges. Journal of adhesion science and technology. 2009; 23:1201-1214.

38. Reisa AE, Gianninia M, Bovi Ambrosanob GM, Chan DCN. The effects of filling techniques and a low viscosity composite liner on bond strength to class II cavities. J Dent 2003;31:59-66.

39. Roulet JF. Benefits and disadvantages of tooth-colored alternatives to amalgam. J Dent 1997;25:459-473.

40. Yap AUJ. Effectiveness of polymerization in composite restoratives claiming bulk placement: impact of cavity depth and exposure time. J Oper Dent 2000;25:113-120.

41. Cramer NB, Stansbury JW, Bowman CN. Recent advances and developments in composite dental restorative materials. J Dent Res 2011;90:402-416.

42. Ellakwa A, Cho N, Lee IB. The effect of resin matrix composition on the polymerization shrinkage and rheological properties of experimental dental composites. Dent Mater 2007;23:1229-1235.

43. Ferracane JL, Berge HX, Condon JR. In vitro aging of dental composites in water: effect of degree of conversion, filler volume and filler/matrix coupling. J Biomed mater res 1998;42:465-472.

44. Hashimoto M, Ohno H, Sano H, Tay FR, Kaga M, Kudou Y, Micro morphological changes in resin-dentin bonds after 1 year of water storage. J Biomed Mater Res 2002;63:306-311.

45. Pashley DH, Tay FR, Yiu C, Hashimoto M, Breschi 1, Carvalho RM. Collagen degradation by host-derived enzymes during aging. J Dent Res 2004;83:216-221. 
46. Khoroushi M, Rafiei E. Effect of thermocycling and water storage on bond longevity of two self-etch adhesives. General Dentistry 2013;3:39-44.

47. Shinohara MS, De Goes MF, Schneider. Fluoridecontaining adhesive: durability on dentin bonding. Dent Mater 2009;25:1383-1391.

48. Ansari ZI, Sadr A, Moezizadeh M. Effects of one-year storage in water on bond strength of self-etching adhesive to enamel and dentin. Dent Mater J 2008;27:266-272.

49. Nikaido T, Inoue G, Takagaki. New strategy to create "super dentin" using adhesive technology: reinforcement of adhesive-dentin interface and protection of tooth structures. Japanese Dental Science Review, 2011;47:31-42.

50. Martins GC, Calixto AL, Gomes OMM, Loguercio AD, D'Alpino PHP, Reis A. Effect of water storage on resin-dentin bond strengths formed by different bonding approaches. Indian J Dent Res 2009;20:431-436.

51. Mendez JC, Pabon GE, Hilgenberg SP, Garcia EJ, AramaCorrea B. Effect of water storage on microtensile bond strength of a two-step self-etch adhesive and a twostep etch and rinse adhesive. Acta Odontol Latinoam 2012;25:176-80

52. Feitosa VP, Fugolin AP, Correr AB, Correr-sobrinhol L, Consan $\mu$, Watson TF. Effects of different photopolymerization protocols on resin-dentine $\mu \mathrm{TBS}$, mechanical properties and cross-link density of a nanofilled resin composite. J Dent 2012;40:802-809.

53. Hashimoto M, Ohno H, Kaga M, Endo K, sano H, Oguchi H. In vivo degradation of resin-dentin bonds in humans over 1 to 3 years. J Dent Res 2000;79:1385-1391.

54. DE SA RB, Carvalho AO, Puppin- Rotani RM, Ambrosano GM,Nikaido T, Tagmi J, Giannini M. Effect of water storage on bond strength and dentin sealing ability promoted by adhesive systems. J Adhes Dent 2012;14:543-549.

55. Sezinando A, Perdigao J, Regalheiro R. Dentin bond strengths of four adhesion strategies after thermal fatigue and 6-month water storage. J Esthet restor Dent 2012; 24:345-356.

56. Vidal CM, Pavan S, Briso AL, Bedran-Russo AK. Effects of three restorative techniques in the bond strength and nonoleakage at gingival wall of class II restorations subjected to simulated aging. clin oral Invest 2013; 17:627-633.

57. Reis AF, Giannini M, Pereira PN. Effects of a peripheral enamel bond on the long-term effectiveness of dentin bonding agents exposed to water in vitro. J Biomed Mater Res Part B Appl Biomater 2008;85:10-17.

58. Yuan Y, Shimada Y, Ichinose S, Sadr A, Tagami J, Effects of dentin characteristics on interfacial nanoleakage. J Dent Res 2007;86:1001-1006. 